\title{
On using isoluminant stimuli to separate magno- and parvocellular responses in psychophysical experiments $-A$ few words of caution
}

\author{
B. C. Skottun
}

Published online: 5 January 2013

(C) Psychonomic Society, Inc. 2012

\begin{abstract}
Isoluminant (or equiluminant) color stimuli (i.e., those that contain variations only in chromaticity) have been employed in attempts to separate magno- and parvocellular responses in psychophysical and noninvasive electrophysiological experiments. The justification for this has been the assumption that magnocellular cells, unlike parvocellular neurons, do not respond to stimuli varying only in hue. However, several problems are associated with this notion: (1) under many conditions, magnocellular neurons are not fully silenced at isoluminance, and (2) in many circumstances, parvocellular responses are substantially reduced at isoluminance. To rely upon isoluminant stimuli to "bias" stimuli toward the parvocellular system also faces obstacles. Therefore, caution is required when attempting to use isoluminant color to separate magno- and parvocellular responses.
\end{abstract}

Keywords Equiluminance $\cdot$ Luminance $\cdot$ Vision $\cdot$ Primate $\cdot$ Parallel streams $\cdot$ Color

In the primate visual system, responses to broadband and color-opponent stimuli are processed by separate channels between the retina and cerebral cortex. The two channels are anatomically distinct: originating in different types of retinal ganglion cells, occupying separate layers in the lateral geniculate nucleus, and terminating in separate input layers in the primary visual cortex (i.e., Area V1). The two channels are referred to as the magnocellular and the parvocellular systems (Merigan \& Maunsell 1993; Shapley \& Perry, 1986). Of the two systems, the parvocellular one mediates

B. C. Skottun $(\bowtie)$

Ullevaalsalleen $4 \mathrm{C}$,

0852, Oslo, Norway

e-mail: berntskottun@yahoo.com color opponent responses whereas the magnocellular stream responds to broadband stimuli. In addition to the magnoand parvocellular systems, there is a third, the koniocellular system, that, like the parvocellular system, contains coloropponent neurons (Hendry \& Reid, 2000). The difference between the systems' responses to color and luminance has led several investigators to suggest or imply that it might be possible to use stimuli that vary in color but not luminance-so-called isoluminant or equiluminant color stimuli- to separate magno- and parvocellular responses (or to separate magnocellular responses from parvo- and koniocellular responses) in psychophysical or noninvasive electrophysiological experiments (Ayhan, Bruno, Nishida, \& Johnston, 2011; Braithwaite, Watson, Andrews, \& Humphreys, 2010; Butler et al., 2001; Cicchini, 2012; Foxe et al., 2008; Greenstein, Seliger, Zemon, \& Ritch, 1998; Keri, Kelemen, Benedek, \& Janka, 2004; McLean, Stuart, Coltheart, \& Castles, 2011; Nieuwenhuis, Jepma, La Fors, \& Olivers, 2008; Omtzigt \& Hendriks, 2011; Sartucci et al., 2010; Schechter et al., 2005; Yoonessi \& Yoonessi, 2011).

The justification for this has been the assumption that magnocellular neurons respond to luminance stimuli and not to color stimuli, and therefore will not be activated by isoluminant stimuli, as these vary only in chromaticity and have no variation in luminance. Parvocellular neurons, in contrast - which respond to differences in color, it is assumed - will respond to isoluminant color stimuli-that is, to stimuli that vary only with regard to hue. The overall result according to this reasoning would be that isoluminant stimuli would selectively activate the parvocellular system (or the parvo- and koniocellular systems), because these stimuli silence the magnocellular system while the parvocellular system (as well as, presumably, the koniocellular system) remains responsive. As a result, responses to isoluminant color stimuli, it has been suggested, reflect parvocellular activity (or parvo- and koniocellular activity). 
This assumption has its origin in studies of the late 1970s and early 1980s that indicated that magno- and parvocellular neurons differ fundamentally with regard to their responses to color: De Valois, Snodderly, Yund, and Hepler (1977) recorded the responses for nonopponent and spectrally opponent lateral geniculate nucleus (LGN) cells to isoluminant color and luminance stimuli. They found that "[n]onopponent cells show little if any change in firing from the maintained rate in response to change in only the color of the stimulus pattern. Thus, they did not respond to our equalluminance [i.e., isoluminance] color variations. This is, of course, consistent with reports . . . that such cells are, in effect, color blind" (De Valois et al., 1977, p. 249). In contrast, De Valois et al. (1977, p. 249) found that "[s] pectrally opponent LGN cells respond to lines based on either luminance or color differences." A limitation of these observations in the present context is that the cells were classified as nonopponent and spectrally opponent cells, rather than in terms of magno- and parvocellular neurons. However, given that the nonopponent and spectrally opponent cells are generally linked, respectively, to the magnoand parvocellular systems, these observations are likely to have contributed to the view that magnocellular cells are silenced at isoluminance.

Kruger (1977) found pronounced color responses to large-field stimuli in the dorsal layers of the LGN, whereas the ventral layers were less responsive. Since the four, or two (depending on how the structure is sectioned), dorsal layers of the LGN are parvocellular, and the two ventral layers are magnocellular, the observations of Kruger indicate that magnocellular cells are less responsive to color than are parvocellular neurons. Consistent with this finding, Hicks, Lee, and Vidyasagar (1983) found that, in contrast to parvocellular cells, magnocellular neurons respond poorly to color gratings.

The notion that isoluminant stimuli can isolate parvocellular responses (or parvo- and koniocellular responses) is commonly attributed (as indicated by citations) to Livingstone and Hubel (1987, 1988). Livingstone and Hubel (1987, p. 3421) wrote of magnocellular responses to color edges, "At some setting of relative brightness of red and green, the cell should show no change in firing rate when the border crosses its receptive field." (The word "should" is noteworthy in this context.) This conclusion was based on the results of Kruger (1979) and Hicks et al. (1983). Livingstone and Hubel (1988) particularly emphasized the observation of Kruger (1979) that $75 \%$ of 33 magnocellular cells did not respond to a color border (the stimuli were referred to as "heterochromatic stimuli" and consisted of slits of one color surrounded by another color) at some relative brightness. Livingstone and Hubel (1988) drew the conclusion from this work that magnocellular neurons are "colorblind." As additional support for this conclusion were taken the observations that stereopsis and motion perception are reduced at isoluminance ("both motion perception and stereoscopic depth perception are lost at equiluminance" Livingstone \& Hubel, 1988, p. 746). This was interpreted by them as meaning that motion perception and stereoscopic depth perception are carried out by the magnocellular system. Together, these observations were taken to mean that magnocellular neurons are silenced at isoluminance. However, as will be seen, more recent recordings from individual magnoand parvocellular neurons have shown the situation to be more complicated.

\section{Magnocellular responses at isoluminance}

Several researchers have studied magnocellular responses to isoluminant stimuli. In the already mentioned study of Kruger (1979), the fact that $75 \%$ of the magnocellular cells did not respond to wavelength substitution at some of the luminance ratios tested entails that the remaining $25 \%$ of the cells did respond to such substitutions at all luminance ratios. In fact, what Kruger (1979, p. 1352) actually reported was that " $1 / 4 \ldots$ of the cells responded to moving heterochromatic stimuli at all luminance ratios." Kruger also tested the responses of magnocellular cells to large-field stimuli. These consisted of large uniform fields alternating in color between yellow and green. Responses were recoded at a series of different ratios of yellow to green light. Out of the 33 magnocellular cells, all but two responded to large-field wavelength substitution at all of the luminance ratios tested. These results indicate, therefore, that it is possible to obtain responses to isoluminant stimuli in a substantial number of magnocellular neurons. Moreover, they suggest that the degree to which magnocellular neurons respond to isoluminant stimuli depends on the stimuli's spatial parameters.

Lee, Martin, and Valberg (1988) investigated the effect of isoluminance upon monkey retinal ganglion cells that, on the basis of their response properties, were identified as belonging to the magnocellular stream. Lee et al. (1988) found that "phasic" cells, which they assumed to be magnocellular cells, showed a pronounced response reduction at isoluminance. However, the responses, they noted, were generally not completely abolished under this condition. In the words of Lee et al. (1988, p. 329): "It was seldom possible to abolish completely phasic cell responses" (see, e.g., Figs. 6 and 10 of Lee et al., 1988).

The responses of magnocellular lateral geniculate nucleus (LGN) neurons to isoluminant stimuli have been studied extensively in the laboratory of Peter Schiller (Logothetis, Schiller, Charles, \& Hurlbert, 1990; Schiller \& Colby, 1983; Schiller, Logothetis, \& Charles, 1991). Using red and green spots, Schiller and Colby found that "magnocellular broad band cells cannot be nulled but can be balanced" (Schiller \& 
Colby, 1983, p. 1636). By "balanced," they meant that the responses to red and green stimuli could be made to become equal.

Schiller and Colby (1983) also found that neurons in the magnocellular layers of the LGN respond to color borders (i.e., borders separating areas with different hues of the same luminance). This has since been supported by Kaiser, Lee, Martin, and Valberg (1990), who obtained responses in phasic ganglion cells (i.e., the retinal ganglion cells assumed to belong to the magnocellular system) to minimally distinct borders. (See also Lee \& Sun, 2009.)

The studies of Logothetis et al. (1990) and Schiller et al. (1991) also demonstrated that going from luminance stimuli to isoluminant color stimuli reduces the responses of magnocellular neurons, but does not completely abolish them. In fact, Logothetis et al. found that the reductions in magnocellular cells were not statistically different from those in parvocellular cells (see below).

The experiments of Logothetis et al. (1990) were criticized by Shapley and Hawken (1999) on the grounds that silencing of magnocellular neurons at isoluminance requires that stimuli "stimulate only the M-cell receptive field centers" and that "using a variety of spatiotemporal stimuli, some of which isolate receptive field center responses and some of which do not, as was done by Logothetis et al., (1990) is irrelevant to the issue of whether a specific class of spatial stimuli would enable M-signals to be nulled out by equiluminance" (Shapley \& Hawken, 1999, p. 232). This observation may be appropriate with regard to single cells; however, it may be less pertinent when applied to psychophysical tests and electrophysiological studies, such as visually evoked potentials (VEPs). This is because these types of studies involve responses from a large number and a large variety of cells. Testing one individual cell with a variety of stimuli is in some respect equivalent to using a fixed stimulus to test a variety of cells. The activation of a large number of cells would occur in many psychophysical experiments and in electrophysiological tests (such as, e.g., in the case of VEPs) that are based on eliciting responses from large numbers of neurons.

The observation that magnocellular cells are more nearly silenced at isoluminance when the stimuli are confined to the receptive field centers is supported by the work of Smith, Lee, Pokorny, Martin, and Valberg (1992) and Lee and Sun (2009). These authors found that responses to isoluminant color from phasic retinal ganglion cells were greater when the stimuli were larger than when they were small and centered upon the receptive field center.

The observations of Smith et al. (1992), Shapley and Hawken (1999), and Lee and Sun (2009) make the point that in order to silence a magnocellular cell, or to obtain a minimum response from such a cell, an isoluminant stimulus needs to be tailored to the particular neuron under study. For researchers to do this requires, however, that they identify the individual neuron under study. In the cases of psychophysical tests and tests that involve the activation of large numbers of cells, this is generally not the case.

It should also be noted that the response minima for alternating isoluminant stimuli do not always occur when the two alternating stimuli are $180 \mathrm{deg}$ out of temporal phase. Smith et al. (1992; see also Lee \& Sun, 2009) found minimum responses at a 180 -deg phase separation when the flicker frequency was (approximately) above about $20 \mathrm{~Hz}$ (see Fig. 9 of Smith et al., 1992). However, at lower temporal frequencies, it was found that the smallest responses do not occur when the phase difference is $180 \mathrm{deg}$.

Derrington, Krauskopf, and Lennie (1984) made use of a color space in which one axis represented luminance, the second axis formed a "constant-B axis" (in which excitation of the short-wavelength cones did not vary), and the third axis was a "constant $R$ \& $G$ axis" in which chromaticity varied without changing the excitation of the medium- or longwavelength cones. Variations in luminance were expressed as elevations, so that isoluminance was represented by a horizontal plane (an elevation of $0 \mathrm{deg}$ ). Null-planes for various lateral geniculate cells were determined, and using a uniform-field stimulus, magnocellular cells were found to have an average elevation of $23.2 \mathrm{deg}$. However the elevation dropped to $9.7 \mathrm{deg}$ when gratings of the cell's optimal spatial frequency were employed. (For comparison, two classes of parvocellular cells were defined, one with a null-plane elevation of $51.5 \mathrm{deg}$, and one with an elevation 76.7 deg.) This (again) indicates that the degree to which magnocellular cells can be silenced at isoluminance depends on the stimulus parameters. Derrington et al. (1984, p. 264) concluded that "virtually all magnocellular units have chromatically opponent receptive fields in which the antagonistic mechanisms are segregated spatially" and that the medium- and long-wavelength cones contribute differently to the center and surround in most magnocellular cells. (Lee \& Sun, 2009, proposed that the receptive fields of retinal magnocellular cells - that is, parasol ganglion cellscan be understood as a chromatic receptive field superimposed on a center-surround structure.)

Another problem is that variability exists in the isoluminant null-points of individual magnocellular neurons (Cavanagh, 1991; Cavanagh \& Anstis, 1991). Also, Lee et al. (1988) found some degree of interunit variability with regard to minimum response points in phasic retinal ganglion cells (see their Fig. 10). These findings suggest that it may not be possible for a single stimulus to match the minima in all of the neurons in the magnocellular system.

In summary, the studies of magnocellular responses to isoluminant stimuli have revealed that (1) magnocellular responses to isoluminant stimuli are weak, but the cells are generally not silent, and (2) the degree to which magnocellular responses are reduced at isoluminance depends on the stimulus parameters. 


\section{Parvocellular neurons at isoluminance}

The effects of isoluminance upon parvocellular neurons have also been investigated. Schiller and Colby (1983) compared responses from magno- and parvocellular cells to red-green color substitution. The stimuli consisted of spots centered on the cells' receptive fields. It was found that parvocellular neurons' responses to color substitution could be silenced to a greater degree than those of magnocellular cells by adjusting the relative intensities of the red and green stimuli. This is substantially the opposite of what was postulated by Livingstone and Hubel (1987, 1988), who attributed this finding to the use of stationary stimuli.

Also, Logothetis et al. (1990) found that many parvocellular neurons have reduced responses at isoluminance, and Merigan and Maunsell (1993, p. 391) noted that "the P pathway is not fully functional with isoluminance stimuli." Logothetis et al. calculated the average response reduction for a red-green ratio of 0.63 , which was the ratio that, on average, gave the greatest response reduction in magnocellular cells. It was found that the reductions for magno- and parvocellular cells were 3.5 and 2.6 fold, respectively. Not only was the difference between these values relatively modest, it was also not statistically significant.

The finding that parvocellular neurons under many conditions are substantially insensitive to isoluminant stimuli is consistent with other observations. Color-opponent cells in the LGN (i.e., parvo- and koniocellular cells) respond to high-spatial-frequency luminance stimuli, but not to isoluminant stimuli, at these frequencies (see Fig. 1). This indicates that, in the case of high-spatial-frequency stimuli,

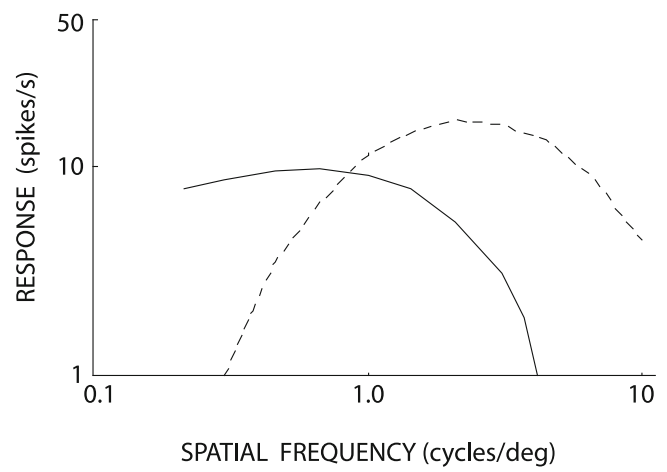

Fig. 1 Response as a function of spatial frequency for red-green isoluminant stimulation (solid line) and luminance stimulation (dashed line) for a color-opponent lateral geniculate nucleus cell (i.e., presumably a parvocellular cell). (The data have been replotted from Fig. 7.8 of De Valois \& De Valois, 1990, which in turn was replotted from Blanckensee 1981.) As can be seen, although the cell responds to luminance stimulation at higher spatial frequencies, it responds to isoluminant stimuli only at low spatial frequencies. This means that this cell would be silenced, or have greatly reduced responses, at isoluminance when tested with high-spatial-frequency stimuli. There are reasons to believe that a similar scenario applies in the case of temporal frequency (see the text for details)

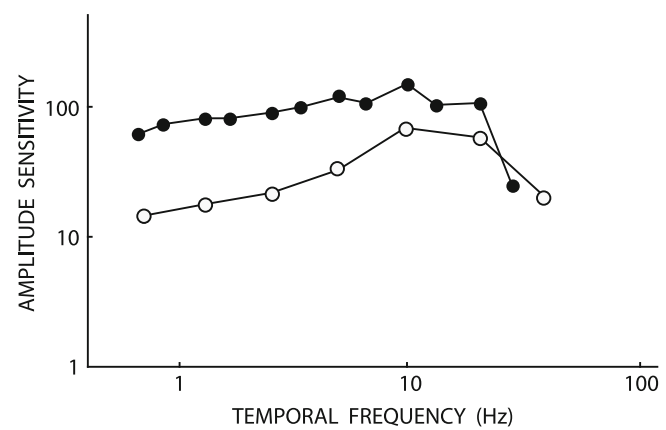

Fig. 2 Temporal contrast sensitivity of tonic ganglion cells (i.e., retinal cells belonging to the parvocellular system) to luminance (open symbols) and chromatic modulation (filled symbols). The modulation was calculated in terms of cone contrasts. Data are replotted from Figs. 3 and 4 of Lee et al. (1990) and were obtained at a retinal illumination of $300 \mathrm{Td}$

parvocellular responses may be reduced, or even silenced, at isoluminance.

Omtzigt and Hendriks (2011, p. 604) wrote with regard to the identification of letter stimuli: "Because of the magnocellular system's poor colour coding, poorer letter identification under colour than under luminance contrast may be attributed to loss of magnocellular function, provided that colour and luminance contrasts are matched for performance on a reference stimulus." That this should be the case is not clear. If the identification of the letter depends on high spatial frequencies - that is, on fine details - one would expect, from Fig. 1, that identification based on isoluminant stimuli would also suffer if it were mediated by parvocellular activity.

A similar observation applies to temporal frequency. This is illustrated in Fig. 2. As can be seen, parvocellular cells' sensitivity is higher for chromatic modulation at low and medium temporal frequencies. However, at the highest frequencies, the sensitivity to chromatic modulation falls off relative to the sensitivity to luminance modulation. Thus, at the very highest frequencies, parvocellular cells may respond to luminance flicker but not to chromatic flicker.

Some evidence suggests that a slight latency difference between center and surround in color-opponent cells causes parvocellular cells to respond to luminance stimuli but not to isoluminant color stimuli at high temporal frequencies (Gouras \& Zrenner, 1979; see also pp. 224-227 of De Valois $\&$ De Valois, 1990, for a discussion). In the words of De Valois and De Valois (1990, p. 226), the latency difference makes "the center and surround inputs synergistic for luminance and antagonistic for color." This would entail that these cells have reduced responses to isoluminant stimulation, relative to responses to luminance stimuli, at high temporal frequencies. Also, it entails that the fact that human observers can detect luminance flicker at higher temporal frequencies than they can see chromatic flicker does not have to mean that two different systems are at work. 
One further consequence of this finding is that it may be difficult to use transient isoluminant stimuli to isolate parvocellular responses (or parvocellular and koniocellular responses). This is because transient stimuli-that is, those with abrupt onsets and/or offsets - contain a large amount of energy at high temporal frequencies. This limitation is particularly important in connection with certain kinds of tests-for instance, some forms of VEPs, in which it is necessary to have an abrupt stimulus onset, or offset, in order to accurately time neuronal responses.

\section{Isolating magnocellular responses}

While the prominent view has been that isoluminant stimuli selectively elicit parvocellular responses, McLean et al. (2011), on the basis of the observations of Schiller and Logothetis (1990), have proposed the opposite: namely, that isoluminant stimuli can be used to isolate magnocellular responses. Specifically, what these authors proposed is that the upper limit to perceived flicker induced with isoluminant stimuli reflects magnocellular activity. McLean et al. described their method as follows:

[T] he task involves viewing an isoluminant red and green light emitting diode (LED) in which the rate of $\mathrm{red} /$ green flicker is gradually increased until the red/ green LED appears to fuse into a single orange color. This flicker frequency is recorded as a measure of parvocellular temporal resolution as it reflects the point at which this system is no longer capable of discerning the rapid red/green color change. . . . At this frequency, however, the perception of orange flicker persists, as the superior temporal resolution of the magnocellular system is still capable of detecting the transient nature of the stimuli. . . . If the flicker frequency is further increased, eventually the LED appears to fuse into a solid orange light, with this frequency representing the threshold of magnocellular temporal resolution. (McLean et al., 2011, p. 1960)

This proposal faces several difficulties.

One problem is that the flicker is perceived as being orange ("orange flicker"). This implies the involvement of mechanisms responsible for color vision. Color vision is generally held to be mediated by the parvocellular system (or the parvo- and koniocellular systems). It is therefore difficult to argue that "orange flicker" does not in some manner involve the parvocellular system. (It should be noted that there was no orange color in the stimuli. Orange flicker was what was seen. It would seem, however, that having the sensation of an orange color, even if this color is not in the stimuli, would require the involvement of the mechanisms underlying color vision.)
A further problem is that temporal resolution is generally held to reflect temporal filtering in the visual cortex rather than in subcortical parts of the visual system. This applies to both isoluminant flicker and luminance flicker (D'Souza, Auer, Stasburger, Frahm, \& Lee, 2011; Hawken, Shapely, \& Grosof, 1996; Jiang, Zhou, \& He, 2007; Mullen, Thompson, \& Hess, 2010). Therefore, even if it were the case that the red-green and the orange flicker were mediated by, respectively, the parvo- and magnocellular systems, on this basis one could not count on the upper limits of these kinds of perceived flicker represent the temporal limits of the parvo- and magnocellular systems.

The measures of "magnocellular temporal resolution" obtained by McLean et al. (2011) were around $30 \mathrm{~Hz}$ (29.480 and $30.196 \mathrm{~Hz}$ for the two groups of subjects examined in their study). By comparison, Lee, Pokorny, Smith, Martin, and Valberg (1990) found robust modulated responses in both phasic and tonic cells at $39.1 \mathrm{~Hz}$ (see Figs. 7 and 8 of Lee et al., 1990; see also Fig. 3 of Lee, Martin, \& Valberg, 1989). Lee et al. (1990) obtained responses from tonic cells (i.e., retinal parvocellular neurons) to chromatic modulation at temporal frequencies much higher than could be detected psychophysically. In addition, using fMRI, Jiang et al. (2007) found that many areas in human visual cortex respond differently to what is seen as fused heterochromatic flicker and steady illumination. These observations provide further evidence that the ability to perceive flicker is not limited by the subcortical magnoand parvocellular systems, but by cortical filters. Thus, to attribute the highest temporal frequency at which responses to heterochromatic flicker can be perceived as being the temporal limit of the magnocellular system is problematic.

Williams, Mechler, Gordon, Shapley, and Hawken (2004) observed cortical responses to $100-\mathrm{Hz}$ luminance flicker. These would presumably have to be mediated, at least in part, by input from the magnocellular system. It is, therefore, difficult to take seriously the suggestion that a "magnocellular temporal resolution" of about $30 \mathrm{~Hz}$ actually represents the temporal resolution of the magnocellular system.

Also, the notion that the upper limit for seeing red-green flicker represents the "parvocellular temporal resolution" seems problematic. McLean et al. (2011) obtained "parvocellular temporal resolution" values near $21 \mathrm{~Hz}$ (21.226 and $20.632 \mathrm{~Hz}$ for the two groups of subjects tested). Gur and Snodderly (1997) found that 10 out of 12 color-opponent cortical cells in macaque V1 responded to $30-\mathrm{Hz}$ isoluminant flicker. Since these cells, presumably, would be receiving a substantial portion of their input from parvocellular cells, it is difficult to reconcile this with a $21-\mathrm{Hz}$ parvocellular limit. 


\section{Additional confounds and considerations}

The difference between color and luminance responses is not the same as the difference between parvo- and magnocellular responses (Ingling \& Grigsby, 1990; Skottun \& Skoyles, 2008). First, the koniocellular system plays a role in color processing (mainly, it seems, in the processing of yellow and blue stimuli: Roy et al., 2009; Szmajda, Buzas, Fitzgibbon, \& Martin, 2006). Second, the parvocellular system responds to both color and luminance stimuli (as does the magnocellular system, to some degree; see above).

Many psychophysical experiments are cast in terms of the magnocellular versus the parvocellular system. That is, in many articles these are presented as the only alternatives. However, cortical mechanisms should also be considered, since there is ample evidence that they play important roles in color vision. For instance, some aspects of color vision cannot be accounted for on the basis of subcortical mechanisms alone (De Valois \& De Valois, 1993). Also, it has been shown that color signals can be integrated along the trajectory of moving stimuli (Nishida, Watanabe, Kuriki, \& Tokimoto, 2007; Watanabe \& Nishida, 2007). This, it would seem, is difficult to account for on the basis of subcortical entities.

The possibility also exists that neurons in different cortical areas respond differently to isoluminant stimuli. For instance, cells in area MT respond relatively weakly to isoluminant stimuli (Gegenfurtner et al., 1994), whereas cells in area V4 respond more strongly (Schein \& Desimone, 1990; Zeki, 1980). Also, areas V2 and V3 contain many cells responsive to isoluminant color (Kiper, Levitt, \& Gegenfurtner, 1999). Therefore, structures other than the magno- and parvocellular systems need to be considered when interpreting responses to luminance and isoluminant color stimuli.

\section{Discussion}

The review above indicates that considerable difficulties exist in using isoluminant stimuli to separate magno- and parvocellular responses (or to separate magnocellular responses from parvo- and koniocellular responses). The review also makes clear that the degrees to which magnoand parvocellular contributions can be separated using isoluminant stimuli depends on the stimulus parameters. This issue merits a brief discussion.

Following the work of Shapley and Hawken (1999) and of Smith et al. (1992), it appears possible to substantially silence magnocellular cells by tailoring the stimuli to the response characteristics of the specific cell under study, so that only its center mechanism is activated. There are, however, limits to using this approach in psychophysical experiments and in noninvasive electrophysiological experiments in which the stimuli activate substantial numbers of neurons.

One might think that using stimuli consisting of small spots or dots could avoid the problem. This is, however, far from certain, since small stimuli, although they could activate only center mechanisms in some cells, would cover parts of the center and surround in other cells. In the case of luminance stimuli, one might perhaps expect responses from the cells whose receptive-field centers are stimulated to dominate the responses, since the surround generally provides a suppressive effect. Thus, the neurons stimulated in both their centers and their surrounds would be activated to a lesser degree than would the cells that are stimulated only in their centers. Therefore, in the case of luminance stimuli, it might be expected that responses from small spots would largely reflect the stimulation of center mechanisms. However, in the case of isoluminant stimuli the situation may be different, since, as has just been mentioned, magnocellular neurons generate responses at isoluminance when both center and surround are activated. Thus, responses to small isoluminant spots, as far as the magnocellular neurons are concerned, might reflect, to a large extent, stimulation falling on both the center and the surround.

A further issue with regard to stimuli that activate several neurons is that, as was pointed out above, there is intercell variability with regard to the color ratio of the light that gives the smallest response. Thus, the stimulation that elicits a minimal response from some neurons may elicit a pronounced response from other cells.

The finding (Derrington et al., 1984) that the null-plane was more closely aligned with the isoluminance plane when a moderately high-spatial-frequency stimulus was used than when uniform fields of alternating hues were used suggests that using isoluminant stimuli of medium to high spatial frequency may silence the magnocellular system. The problem in this connection is that parvocellular responses to isoluminant color are also highly suppressed at high spatial frequencies, as is shown in Fig. 1. Thus, one needs to select a spatial frequency that is sufficiently high to generate little response from magnocellular cells, but not so high as to abolish responses to chromatic stimuli from parvocellular cells.

The data from Granger and Heurtley (1973) indicated that the spatial frequency should be kept below about 3 cycles/deg. This places restrictions on the use of stimuli with sharp edges, since these inevitably contain energy at high spatial frequencies. A similar issue may be present with regard to temporal frequencies (see Fig. 2). In this case, the work of Kelly (1975) suggests that the energy of the stimulus should be at a modulation frequency below approximately $10 \mathrm{~Hz}$. This means that stimuli with sharp transients should be avoided. 
The fact that color-opponent cells can have markedly different tuning properties under luminance and isoluminantcolor conditions entails that selective activation of the parvocellular system cannot be achieved by merely taking any given stimulus and turning it into an isoluminant stimulus. This has already been noted by Shapley and Hawken (1999, p. 233), who observed that "the chromatic system may have quite a different 'window of visibility' in the dimensions of size or time duration, or temporal frequency. Therefore, a change of performance at equiluminance, keeping all other spatial and temporal variables fixed, may be misleading."

With regard to high-spatial-frequency chromatic stimuli, there is also the issue of chromatic aberration. The term "chromatic aberration" refers to the fact that light of different wavelengths is refracted to different degrees (Thibos, Bradley, Still, Zhang, \& Howarth, 1990). Thus, in the case of heterochromatic stimuli, it is possible that such aberration might cause various parts of the light spectrum to be focused at different focal lengths. This could cause an isoluminant stimulus to introduce luminance variations in the retinal image. Such artifacts are likely to be most pronounced in stimuli containing high spatial frequencies (e.g., sharp edges). The reason for this is that, since the cycle width is inversely related to spatial frequency, a high-spatialfrequency component has a small cycle width. Thus, a given amount of retinal blur makes up a larger fraction of the cycle of a high-spatial-frequency component than of a lowfrequency one.

It is possible to counteract the effects of chromatic aberration to some degree with the use of "achromatizing lenses" in front of the subjects' eyes. (For a brief discussion of achromatizing lenses and the need for their use in vision research, see Howarth \& Bradley, 1986.)

Rather than trying to use isoluminant stimuli to achieve a complete isolation of parvocellular responses, an alternative approach has been to use isoluminance to merely "bias" the stimuli toward the parvocellular system (as did Butler et al., 2001; Schechter, Butler, Silipo, Zemon, \& Javitt, 2003; and Schechter et al., 2005) or to make them "favor" the parvocellular system (Greenstein et al., 1998). This, however, creates its own problems. First, as was noted above, in many cases parvocellular responses are also reduced at isoluminance. Second, if the responses under study depend on contrast, then in order to compare the responses to luminance and isoluminant stimuli, the effective contrasts under the two conditions need to be equated. Unless this is done, it will be unclear whether any of the observed effects are due to color differences or to differences in effective contrast. This problem is not an easy one to solve, since luminance contrast and color contrast are two fundamentally different measures, and as a result are difficult to compare. One may well envision a situation in which going from a luminance stimulus to an isoluminant color stimulus would cause a reduction in effective contrast (or have an effect equivalent to a reduction in contrast) from a relatively high contrast level. Since magnocellular cells have relatively flatter contrast response curves than do parvocellular cells at medium and high contrasts (i.e., parvocellular responses are reduced more severely than magnocellular cells by reductions in contrast at medium and high contrast levels; Kaplan \& Shapley, 1986), this could, at least in theory, cause the shift from luminance to isoluminant color to have the effect of favoring the magnocellular system.

Another possibility would be to use cone contrast. This, however, requires that the spectral distribution of the light in the stimulus be known, since cone contrast is based on the inner product of the light in the stimulus and the individual cone mechanisms (Lee et al., 1989).

Comparing the luminance contrast and color contrast in terms of multiples of threshold is one possible option. This, however, means that threshold contrast, in the case of both luminance and isoluminant color, would need to be determined for each individual subject. This requirement may be particularly important when comparing responses between different groups of subjects.

Another method for equating color and luminance has been proposed by Cavanagh and Anstis (1991). Briefly, their method involves superimposing a luminance and a color grating moving in opposite directions. The relative strengths of the two stimuli are then adjusted until the observer sees a stationary counterphase modulated grating. (The actual method is somewhat more complicated, and the reader is advised to consult Cavanagh \& Anstis, 1991, for the technical details.) However, this method has the limitation that equivalence established in this manner may only be valid for moving stimuli. Since it is plausible that different mechanisms could be involved in the perception of moving and stationary stimuli, it is possible that color and luminance stimuli that were equated using motion stimuli might not be equal in the case of stationary stimuli.

\section{Conclusion}

Single-unit studies have revealed that magnocellular neurons respond much more weakly to isoluminant stimuli than to luminance stimuli. However, so do parvocellular cells under many conditions. To rely on isoluminant color to provide an absolute separation between magno- and parvocellular contributions in psychophysical and noninvasive electrophysiological experiments is highly questionable. For instance, to turn some arbitrary luminance stimulus into an isoluminant stimulus and think that the resulting stimulus will elicit only parvocellular responses is clearly problematic. To use isoluminant color to bias the stimulation away from the magnocellular system also faces difficulties. 
Interpreting results obtained with isoluminant stimuli in terms of magno- and parvocellular contributions needs to be carried out with caution. The need for caution is particularly important in tasks that involve responses from large and diverse sets of neurons.

\section{References}

Ayhan, I., Bruno, A., Nishida, S., \& Johnston, A. (2011). Effect of the luminance signal on adaptation-based time compression. Journal of Vision, 11(7):22, 1-17. doi:10.1167/11.7.22

Braithwaite, J. J., Watson, D. G., Andrews, L., \& Humphreys, G. W. (2010). Visual search at isoluminance: Evidence for enhanced color weighting in standard sub-set and preview-based visual search. Vision Research, 50, 1414-1425.

Butler, P. D., Schechter, I., Zemon, V., Schwartz, S. G., Greenstein, V. C., Gordon, J., ... Javitt, D. C. (2001). Dysfunction of early-stage visual processing in schizophrenia. The American Journal of Psychiatry, 158, 1126-1133.

Cavanagh, P. (1991). The contribution of colour to motion. In A. Valberg \& B. B. Lee (Eds.), From pigments to perception (pp. 151-164). New York: Plenum Press.

Cavanagh, P., \& Anstis, S. (1991). The contribution of color to motion in normal and color-deficient observers. Vision Research, 31, $2109-2148$.

Cicchini, G. M. (2012). Perception of duration in the parvocellular system. Frontiers in Integrative Neuroscience, 6, 14. doi:10.3389/ fnint.2012.00014

Derrington, A. M., Krauskopf, J., \& Lennie, P. (1984). Chromatic mechanisms in lateral geniculate nucleus of macaque. The Journal of Physiology, 357, 241-265.

De Valois, R. L., \& De Valois, K. K. (1990). Spatial vision. New York: Oxford University Press.

De Valois, R. L., \& De Valois, K. K. (1993). A multi-stage color model. Vision Research, 33, 1053-1065.

De Valois, R. L., Snodderly, D. M., Yund, E. W., \& Hepler, N. K. (1977). Responses of macaque lateral geniculate cells to luminance and color figures. Sensory Processes, 1, 244-259.

D’Souza, D. V., Auer, T., Stasburger, H., Frahm, J., \& Lee, B. B. (2011). Temporal frequency and chromatic processing in humans: An fMRI study of the cortical visual areas. Journal of Vision, 11 (8):8, 1-17. doi:pii:8.10.1167/11.8.8

Foxe, J. J., Strugstad, E. C., Sehatpour, P., Molholm, S., Pasieka, W., Schroeder, C. E., \& McCourt, M. E. (2008). Parvocellular and magnocellular contributions to the initial generators of the visual evoked potential: High-density electrical mapping of the "C1" component. Brain Topography, 21, 11-21.

Gegenfurtner, K. R., Kiper, D. C., Beusmans, J. M., Carandini, M., Zaidi, Q., \& Movshon, J. A. (1994). Chromatic properties of neurons in macaque MT. Visual Neuroscience, 11, 455-466.

Gouras, P., \& Zrenner, E. (1979). Enhancement of luminance flicker by color-opponent mechanisms. Science, 205, 587-589.

Granger, E. M., \& Heurtley, J. C. (1973). Letters to the editor: Visual chromaticity-modulation transfer function. Journal of the Optical Society of America, 63, 1173-1174.

Greenstein, V. C., Seliger, S., Zemon, V., \& Ritch, R. (1998). Visual evoked potential assessment of the effects of glaucoma on visual subsystems. Vision Research, 38, 1901-1911.

Gur, M., \& Snodderly, D. M. (1997). A dissociation between brain activity and perception: Chromatically opponent cortical neurons signal chromatic flicker that is not perceived. Vision Research, 37, $377-382$
Hawken, M. J., Shapely, R. M., \& Grosof, D. H. (1996). Temporalfrequency selectivity in monkey visual cortex. Visual Neuroscience, 13, 477-492.

Hendry, S. H., \& Reid, R. C. (2000). The koniocellular pathway in primate vision. Annual Review of Neuroscience, 23, 127-153.

Hicks, T. P., Lee, B. B., \& Vidyasagar, T. R. (1983). The responses of cells in macaque lateral geniculate nucleus to sinusoidal gratings. The Journal of Physiology, 337, 183-200.

Howarth, P. A., \& Bradley, A. (1986). The longitudinal chromatic aberration of the human eye, and its correction. Vision Research, 26, 361-366.

Ingling, C. R., Jr., \& Grigsby, S. S. (1990). Perceptual correlates of magnocellular and parvocellular channels: Seeing form and depth in afterimages. Vision Research, 30, 823-828.

Jiang, Y., Zhou, K., \& He, S. (2007). Human visual cortex responds to invisible chromatic flicker. Nature Neuroscience, 10, 657-662.

Kaiser, P. K., Lee, B. B., Martin, P. R., \& Valberg, A. (1990). The physiological basis of the minimally distinct border demonstrated in the ganglion cells of the macaque retina. The Journal of Physiology, 422, 153-183.

Kaplan, E., \& Shapley, R. M. (1986). The primate retina contains two types of ganglion cells, with high and low contrast sensitivity. Proceedings of the National Academy of Sciences USA, 83, 27552757.

Kelly, D. H. (1975). Luminous and chromatic flickering patterns have opposite effects. Science, 188, 371-372.

Keri, S., Kelemen, O., Benedek, G., \& Janka, Z. (2004). Vernier threshold in patients with schizophrenia and in their unaffected siblings. Neuropsychology, 18, 537-542.

Kiper, D. C., Levitt, J. B., \& Gegenfurtner, K. R. (1999). Chromatic signals in extrastriate areas V2 and V3. In K. R. Gegenfurtner \& L. T. Sharpe (Eds.), Color vision-From genes to perception (pp. 249-268). Cambridge: Cambridge University Press.

Kruger, J. (1977). Stimulus dependent colour specificity of monkey lateral geniculate neurones. Experimental Brain Research, 30, 297-311.

Kruger, J. K. (1979). Responses to wavelength contrast in the afferent visual systems of the cat and the rhesus monkey. Vision Research, 19, 1351-1358.

Lee, B. B., Martin, P. R., \& Valberg, A. (1988). The physiological basis of heterochromatic flicker photometry demonstrated in the ganglion cells of the macaque retina. The Journal of Physiology, 404, 323-347.

Lee, B. B., Martin, P. R., \& Valberg, A. (1989). Sensitivity of macaque retinal ganglion cells to chromatic and luminance flicker. The Journal of Physiology, 414, 223-243.

Lee, B. B., Pokorny, J., Smith, V. C., Martin, P. R., \& Valberg, A. (1990). Luminance and chromatic modulation sensitivity of macaque ganglion cells and human observers. Journal of the Optical Society of America. A, 7, 2223-2236.

Lee, B. B., \& Sun, H (2009). The chromatic input to cells of the magnocellular pathway of primates. Journal of Vision, 9(2):15, 1-18. doi:10.1167/9.2.15

Livingstone, M. S., \& Hubel, D. H. (1987). Psychophysical evidence for separate channels in the perception of form, color, movement, and depth. Journal of Neuroscience, 7, 3416-3468.

Livingstone, M., \& Hubel, D. (1988). Segregation of form, color, movement, and depth: Anatomy, physiology, and perception. Science, 240, 740-749.

Logothetis, N. K., Schiller, P. H., Charles, E. R., \& Hurlbert, A. C. (1990). Perceptual deficits and the activity of the color-opponent and broadband pathways at isoluminance. Science, 247, 214-217.

McLean, G. M. T., Stuart, G. W., Coltheart, V., \& Castles, A. (2011). Visual temporal processing in dyslexia and the magnocellular deficit theory: The need for speed? Journal of Experimental Psychology. Human Perception and Performance, 37, 1957-1975. 
Merigan, W. H., \& Maunsell, J. H. (1993). How parallel are the primate visual pathways? Annual Review of Neuroscience, 16, 369-402.

Mullen, K. T., Thompson, B., \& Hess, R. F. (2010). Responses of the human visual cortex and LGN to achromatic and chromatic temporal modulations: An fMRI study. Journal of Vision 10(13):13, 1-19. doi:10.1167/10.13.13

Nieuwenhuis, S., Jepma, M., La Fors, S., \& Olivers, C. N. L. (2008). The role of the magnocellular and parvocellular pathways in the attentional blink. Brain and Cognition, 68, 42-48. doi:10.1016/ j.bandc. 2008.02.119

Nishida, S., Watanabe, J., Kuriki, I., \& Tokimoto, T. (2007). Human visual system integrates colour signals along motion trajectory. Current Biology, 17, 366-372.

Omtzigt, D., \& Hendriks, A. W. (2011). Magnocellular facilitation of flanked-letter identification disappears with strong flanker interference. Journal of Cognitive Psychology, 23, 604-618. doi:10.1080/20445911.2011.575775

Roy, S., Jayakumar, J., Martin, P. R., Dreher, B., Saalmann, Y. B., Hu, D., \& Vidyasagar, T. R. (2009). Segregation of short-wavelengthsensitive (S) cone signals in the macaque dorsal lateral geniculate nucleus. European Journal of Neuroscience, 30, 1517-1526.

Sartucci, F., Borghetti, D., Bocci, T., Murri, L., Orsini, P., Porciatti, V., \& Domenici, L. (2010). Dysfunction of the magnocellular stream in Alzheimer's disease evaluated by pattern electroretinograms and visual evoked potentials. Brain Research Bulletin, 82, 169-176.

Schechter, I., Butler, P. D., Silipo, G., Zemon, V., \& Javitt, D. C. (2003). Magnocellular and parvocellular contributions to backward masking dysfunction in schizophrenia. Schizophrenia Research, 64, 91-101.

Schechter, I., Butler, P. D., Zemon, V. M., Revheim, N., Saperstein, A. M., Jalbrzikowski, M., ... Javitt, D. C. (2005). Impairments in generation of early-stage transient visual evoked potentials to magno- and parvocellular-selective stimuli in schizophrenia. Clinical Neurophysiology, 116, 2204-2215.

Schein, S. J., \& Desimone, R. (1990). Spectral properties of V4 neurons in the macaque. Journal of Neuroscience, 10, 3369-3389.

Schiller, P. H., \& Colby, C. L. (1983). The responses of single cells in the lateral geniculate nucleus of the rhesus monkey to color and luminance contrast. Vision Research, 23, 1631-1641.
Schiller, P. H., \& Logothetis, N. K. (1990). The color-opponent and broad-band channels of the primate visual system. Trends in Neurosciences, 13, 392-398.

Schiller, P. H., Logothetis, N. K., \& Charles, E. R. (1991). Parallel pathways in the visual system: Their role in perception at isoluminance. Neuropsychologia, 29, 433-441.

Shapley, R. M., \& Hawken, M. J. (1999). Parallel retino-cortical channels and luminance. In K. R. Gegenfurtner \& L. T. Sharpe (Eds.), Color vision-From genes to perception (pp. 221-234). Cambridge, U.K.: Cambridge University Press.

Shapley, R. M., \& Perry, V. H. (1986). Cat and monkey retinal ganglion cells and their visual functional roles. Trends in Neurosciences, 9. 229-235.

Skottun, B. C., \& Skoyles, J. R. (2008). Visual search: Magno- and parvocellular systems or color and luminance processes? International Journal of Neuroscience, 118, 1259-1567.

Smith, V. C., Lee, B. B., Pokorny, J., Martin, P. R., \& Valberg, A. (1992). Responses of macaque ganglion cells to the relative phase of heterochromatically modulated lights. The Journal of Physiology, 458, 191-221.

Szmajda, B. A., Buzas, P., Fitzgibbon, T., \& Martin, P. R. (2006) Geniculocortical relay of blue-off signals in the primate visual system. Proceedings of the National Academy of Sciences USA, 103, 19512-19517.

Thibos, L. N., Bradley, A., Still, D. L., Zhang, X., \& Howarth, P. A. (1990). Theory and measurement of ocular chromatic aberration. Vision Research, 30, 33-49.

Watanabe, J., \& Nishida, S. (2007). Veridical perception of moving colors by trajectory integration of input signals. Journal of Vision, 7(11):3, 1-16. doi:10.1167/7.11.3

Williams, P. E., Mechler, F., Gordon, J., Shapley, R., \& Hawken, M. J. (2004). Entrainment to video displays in primary visual cortex of macaque and humans. Journal of Neuroscience, 24, 8278-8288.

Yoonessi, A., \& Yoonessi, A. (2011). Functional assessment of magno, parvo and konio-cellular pathways: Current state and future clinical applications. Journal of Ophthalmic and Vision Research, 6 , 119-126.

Zeki, S. M. (1980). The representation of colours in the cerebral cortex. Nature, 284, 412-418. 